\title{
Reintegrating socially excluded individuals through a social enterprise intervention
}

Authors: Dr Fred Seddon, Dr Richard Hazenberg \& Professor Simon Denny, University of Northampton, UK.

\begin{abstract}
This research project reveals participant perceptions of an employment enhancement programme, run by a social enterprise and designed to reintegrate socially excluded individuals into society. The research participants were the social entrepreneur, staff at the social enterprise, the programme attendees and a representative from an external referral agency. Participants engaged in semi-structured interviews with a researcher designed to elicit participant perceptions of the programme. Results of the analysis of the interviews revealed six emergent themes that were interpreted by the researchers as: 'social mission focus', 'heroic social entrepreneur', 'social impact', 'recidivism', 'the programme' and 'programme attendees'. Results of the analysis reveal that all research participants reported the programme helped to re-socialise the programme attendees and increased their selfconfidence and self-esteem. Participants also believed programme attendees acquired important skills and qualifications in general warehouse activities and forklift truck driving, which would greatly increase their future employability. Programme attendees indicated the 'real world' working environment was important to their feelings of success on the programme. Social enterprise staff expressed concerns about potential 'mission drift' resulting from the demands of scaling up the logistics business to achieve the 'double bottom line'.
\end{abstract}

\section{Introduction}

Socially excluded individual's problems are often multi-faceted and it has long been recognised that a 'holistic' approach is required to assist them in their reintegration into society (Burnett, 2004; Cohen, 1985; Hannah-Moffat, 2005; McNeill and Weaver, 2010; Mawby, Crawley and Wright, 2010). In the UK policy context, social exclusion is defined as: "a shorthand term for what can happen when people or areas suffer from a combination of linked problems such as unemployment, poor skills, low incomes, unfair discrimination, poor housing, high crime, bad health and family breakdown" (Office of the Deputy Prime Minister [ODPM] 2004:4). If an individual suffers from a combination of these problems they are more likely to be socially excluded and their social exclusion can be described as multidimensional (Teasdale, 2010). Small firms and entrepreneurship have engaged with 
combating social exclusion but this potential solution has been described as over optimistic (Blackburn and Ram, 2006). Blackburn and Ram (2006), argue that a clearer understanding of the complex multidimensional concept of social exclusion is required before making overinflated claims that small business activity can significantly combat social exclusion. This paper reports a research study that investigated referral, provider and participant perceptions of a social enterprise intervention (SEI) programme and examines the relationship between the multifaceted nature of social exclusion and the role of SEI programs in combating it through employment, training or self-employment. The contribution to knowledge provided by this paper is the identification of a hybrid type of SEI based upon the 'vision' of a 'heroic' social entrepreneur (Dees, et al, 2001; Dart, 2004). This hybrid SEI provides training in a 'real' working environment that allows socially excluded individuals to enhance their employment potential, whilst at the same time socially integrating them into their working environment.

\section{Literature Review}

The 'Emergence de L'Economie Sociale' (EMES) network has been instrumental over the last fifteen years in mapping and defining social enterprise typologies across Europe. The EMES network split the definition of a social enterprise into four economic dimensions (continuous production/sales activity; high degree of autonomy; significant level of economic risk; a minimum amount of paid work) and five social dimensions (community benefit; citizen-led; democratic decision-making; participatory nature; limited profit distribution) (Borzaga and Defourny, 2001). However, within this overall typology lie several different types of social enterprise operating across different sectors (e.g. health, social care, employment etc.) and this includes 'Social Enterprise Interventions' (SEIs). An SEI, also 
known as Work Integration Social Enterprise (WISE), assists people on the margins of society and is intended to prevent their permanent exclusion from the labour market and civil society (Spear \& Bidet, 2005). Prior research by the EMES network identified six main types of SEI operating in Europe. These were: 'worker cooperatives'; 'community businesses'; 'social firms'; 'intermediate labour-market organisations' (ILMOs); 'voluntary organisations'; and 'commercial integration organisations' (for a full description of these six types see: Defourny and Nyssens, 2006). Whilst there has been some research conducted into the effects that SEIs have upon their beneficiaries, most notably the 'Performance socioéconomique des entreprises sociales d 'insertion par le travail' (PERSE) study (for a full description of this research see: Campi, Defourny and Grégoire, 2006; Gardin, 2006), this research remains limited methodologically (Hazenberg, 2012). Indeed, the effect of SEIs on their beneficiaries is an underdeveloped area (Peattie \& Morley, 2008) and is further complicated by the notion that employment reintegration is not the sole objective of SEIs, which also seek to raise an individual's human and social capital (Nyssens and Platteau, 2006). Therefore an inductive approach to analysis of data rather than testing existing theory is advantageous (Teasdale, 2010).

Fergus and Islam (2008) applied an inductive approach in a qualitative evaluation of an SEI, which was a vocational training program for homeless street-living young adults in the US. The research employed two formative and one summative focus group discussions with clients of the program in order to reveal their perceptions of the outcomes of the SEI project. Open-ended questions were employed, which were designed to explore client perceptions of the project implementation and outcomes Analysis of the data employing grounded theory revealed emergent outcome themes, which included: family respect, self-esteem, goal orientation, labour and social networks, delinquent behaviour and social perceptions of 
homeless youth. However, Fergus and Islam's (2008) research only elicited the client's perspective of the programme. Indeed, a more complete perception of the programme could have been provided by also eliciting the perceptions of the programme delivery staff. A further issue with this study was that the SEI programme adopted vocational training methods with an emphasis on self-employment, which overlooked the potential employment prospects for the clients. Also, although the SEI programme host agency sponsored the project, provided project space, equipment, clinical and case-management staff, the programme also employed a graphic design instructor and staff from a local art's institute in addition to two clinical mentors. This extensive provision not only made the SEI costly to deliver but could have also created an 'artificial' environment not-unlike the 'education environment' often rejected by hard to reach socially excluded individuals.

A study by Teasdale (2010) also examined the impact SEIs can have on social disadvantage. In the study Teasdale argues that only measuring the quantitative outcomes of SEIs on social exclusion gives an incomplete picture and that qualitative outcomes (e.g., self-esteem) help to develop an understanding of the overall effects of SEIs on exclusion. Teasdale (2010:100) proposes dimensions of exclusion and identifies the 'lower levels of the dimension of exclusion'. This sub-dimension of social exclusion is exemplified by a socially excluded individual being reintegrated within a specific group setting but that individual remaining socially excluded in relation to the country in which they are living. Teasdale's (2010) research suggested that the multidimensional nature of disadvantage meant that the impact SEIs can have on exclusion is marginal and that job creation is achieved more successfully by SEIs when an implicit economic focus is adopted. However, economic focus can result in providing employment within an area but more socially-orientated SEIs can provide space for excluded individuals to bond together (Teasdale, 2010). Teasdale's findings support the 
findings of research that drew evidence from a study of SEIs in Bristol, UK, which raised the question of whether it was the role of the social economy to return the socially disadvantaged back into the formal economy (Amin, 2009). Amin (2009) concluded that this expectation was misguided, unrealistic and overly ambitious. In Amin's study this viewpoint was exemplified by individuals with limited skills and experience, from socially disadvantaged backgrounds, volunteering for work experience as a way back into the mainstream economy. Many individuals were found to gain little from this experience in terms of motivation or employability because they lack interest, learn little and return to unemployment. Amin (2009) attributes this failure to transition to employment to client apathy and resentment, especially those who are there because they risk losing their benefits by refusing the opportunity to engage with the SEI. Examples of successful transition to employment tend to be rare and mostly result when the venture itself is able to offer paid work (Amin, 2009). Interestingly, research by Hazenberg, et al. (2013) did identify that SEI interventions produced positive psychological benefits (in the form of increased general self-efficacy) for socially excluded individuals that engaged with employment enhancement training. However, whilst positive outcome benefits were identified, there was no causal link identified between this and employment. This highlights the multifaceted challenges facing SEIs in preparing socially excluded individuals for employment. Indeed, as social exclusion may be regarded as multidimensional and have varying dimensions of exclusion (Teasdale, 2010), SEI programmes should be tailored to the needs of the socially excluded individual if they are to be beneficial to their clients.

A distinction between SEI types was reported in a study by Vidal (2005), which was conducted with the managing directors of 15 SEIs. Vidal's study reported findings that revealed two types of SEI, Type A: 'intermediate companies' that act as a "bridge" between 
the disadvantaged worker and the normal labour market and Type B: 'end employers' that aim to provide stable jobs for the disadvantaged worker. Type A prioritises care-based and training activities and Type B focuses more on productive activities but still seeks social integration. Also noted in the research was that Type A SEIs, which are considered to be intermediate employers have workers, who joined as participants but have been there so long they cannot, nor should not, still be considered participants (Vidal, 2005). A study by Spear and Bidet (2005) defined SEIs by their integration objectives, training and job contracts, and target groups.

- Integration objectives (i.e. training/employment mix) the extent of the focus on social integration and professional skills and the transitional/permanent nature of the employment,

- Training and job contracts (i.e. mix of formal and informal training) leading to contracts as trainees, short-term, temporary or permanent contracts.

- Target groups (i.e. specific or general target groups) some employment will need to be permanently subsidised to prevent recidivism into unemployment due to attitudinal and cultural problems associated with 'difficult to employ' individuals.

Types of SEI, based on the distinctions made by Vidal (2005) and Spear and Bidet (2005), can be influenced by the perspectives of the social entrepreneur(s). Vidal (2005) argued that SEIs facilitate the growth of the 'social entrepreneur' and she called for investigation of the social entrepreneur as "a strategic element in an innovative, dynamic model for social enterprises" (Vidal, 2005: 824). Some prior studies have examined the role of the social entrepreneur who is attempting to reintegrate socially excluded individuals and found that this role tends to be undertaken by compassionate, well-connected, persuasive, risk-taking social entrepreneurs (Leadbeater, 1997; Spinoza, et al, 1997). This type of social entrepreneur 
is often referred to as 'heroic', driving the social enterprise to tackle societal problems and being catalysts for social change (Dees, et al, 2001; Dart, 2004). Nicholls, (2006) describes these individuals as visionaries who will stop at nothing and he encourages their support. However, this type of 'heroic' social entrepreneur often feel their vision alone validates their social impact and as a result fail to recognise the need to measure it (Seddon, Hazenberg and Denny, under review). It is generally acknowledged that evaluating the social impact performance of a social enterprise is at least as important as measuring its viability but much more difficult to measure (Lane and Casile, 2011). When an organisation has two or three competing social missions, what to measure can be difficult to answer and should also take into consideration what would have happened without the social enterprise's intervention. Social enterprises also need to develop multidimensional performance measurement systems to evaluate the success of the specific environment in which they operate (Lane and Casile, 2011). McLoughlin et al, (2009) proposes the SIMPLE methodology (Social Impact for Local Economies), which involves measuring output, outcome and impact. For example, if the focus of the social mission is on prisoner rehabilitation, levels of recidivism (output), improvements in prisoners' psychological states of mind (outcome) and cost savings to society (impact) would all require measurement if a robust measure of social mission performance is to be achieved. However, there is a tendency for SEIs to focus on qualitative data for evaluation purposes in programmes with competing social missions. In their conceptual paper, which maps out a framework for performance measurement in social entrepreneurship ventures, Lane and Casile (2011) report that of 14 empirical studies they reviewed, stories and testimonials of success were employed by $76 \%$ of the social enterprises involved in their study, even though more rigorous evaluation tools were being experimented with. Lane and Casile (2011) propose this is because anecdotal evidence is easier to collect and interpret in situations when the definition of success is not clear or universally agreed 
upon. Lane and Casile, (2011) conclude that performance measurement for SEIs is fraught with complexity but should map the progress towards the completion of the social mission.

\section{Summary}

The multidimensional nature of social exclusion is well documented (see Burnett, 2004; Cohen, 1985; Hannah-Moffat, 2005; McNeill and Weaver, 2010; Mawby, Crawley and Wright, 2010; Teasdale, 2010). Many SEIs have provided programmes to enable socially excluded individuals to reintegrate into society, especially through self-employment but according to prior research, the role of small firms and entrepreneurship in combating social exclusion has been described as over optimistic (Blackburn and Ram, 2006; Amin, 2009). There is evidence to suggest that social exclusion in a multidimensional problem and that there are differing levels of social exclusion (Teasdale, 2010). Therefore, different types of SEI are required that should reflect the specific needs of the socially excluded individual (Vidal, 2005; Spear and Bidet, 2005). Determining the efficacy of SEIs requires more than collecting quantitative output data (McLoughlin, et al, 2009; Teasdale, 2010; Lane and Casile, 2011). More nuanced outcome data (McLoughlin, et al, 2009) collected by applying an inductive approach will provide a more complete picture of the efficacy of SEIs (Teasdale, 2010; Lane and Casile, 2011). However, by collecting data exclusively from SEI participants, as in Fergus and Islam (2008) or exclusively from managing directors, as in Vidal (2005) there is a danger that a one-dimensional view of the efficacy of an SEI will be revealed. By involving the SEI participants, the SEI provider and a referral agency in the research study the resulting view becomes more 'holistic'. In essence such an approach would provide a multi-stakeholder approach to evaluation that was not solely focused upon the social impact on beneficiaries. 


\section{The current study}

The Social Enterprise (SE)

The SE involved in the current research provides a logistics service supplying affordable furniture to blue-chip companies in the UK. Financial surpluses made by the logistics service enable it to fulfil its social mission, which is providing an SEI to enable socially excluded individuals to reintegrate into society and to provide financial support to local community projects. The SEI programme involves helping excluded individuals to increase their employability through the provision of work experience and training in general warehouse skills to its socially excluded programme attendees (PAs). The social entrepreneur, who is the CEO of the SE, believes that the PAs learn valuable warehousing skills through working alongside existing staff. He also believes that in addition to these specific warehousing skills PAs are also being reintroduced to the daily routine of work and the social interaction required in this 'real' working environment. The social entrepreneur who founded the SE has recruited a team of employees, some of whom were employed in the SE after completing the SEI programme. The 'host' logistics business may be regarded as a social enterprise as it is an organisation that generates a trading surplus external to its social goals (Dees, 1998; Zietlow, 2001; Alter, 2006). The SE may be regarded as a 'social business' because it is an economically viable business with a clear social purpose, has a hierarchical decision making process and economic orientation (Westall, 2001). The business also confirms to the UK government's definition of a social enterprise which is: "a business with primarily social objectives whose surpluses are principally reinvested for that purpose in the business or in the community, rather than being driven by the need to maximise profit for shareholders and owners" (Cabinet Office of the Third Sector, 2006:10). 


\section{Aims of the research}

The research seeks to reveal the participants' perceptions of the SEI. Research participants include: the social entrepreneur (CEO and founder of the SE), the SE staff, the program attendees (PAs) and a representative from a local programme referral agency. When revealed, the research participant perceptions will provide a holistic viewpoint of the benefits for PAs resulting from engagement in the SEI.

\section{Method}

Participants

The total number of participants was twenty $(\mathrm{N}=20)$, consisting of 7 PAs; the social entrepreneur, eleven SE staff and 1 representative from a referral agency.

Procedure

Over a period of three weeks all twenty participants engaged in an individual semi-structured interview with a researcher. All participants were invited to take part in the interviews and were afforded the opportunity to refuse to be interviewed if they so wished; none of the participants refused. The interviews were recorded on a digital recorder, and transcribed for future analysis. Interview questions were open ended in nature and differed depending upon the role of the participant in the SEI. The specific interview schedules are provided below. 
Questions for PAs:

1. In what ways do you feel different since starting the programme?

2. How has your daily routine changed since you started the programme?

3. What do you do here?

4. What things are you able to do that you couldn't do before?

5. Describe how you see your future once you have completed the programme.

6. How has your time on the programme changed your attitude towards the reason you were referred here (e.g. offending, addiction, mental health issues)?

Questions entrepreneur and staff:

1. How do you feel the attendees benefit from the programme?

2. How do you define a 'success' with an attendee?

3. How is it rewarding to you working here?

4. How do you see yourself developing here?

5. How does the social nature of the business shape the way you do your job?

6. What is the future for the business and where do you fit into that future?

Questions for the representative of the referral agency:

1. Why do you send your clients here?

2. What is your understanding of what happens here?

3. How do you feel your clients benefit from the programme?

4. How do you define a 'success' with a client here? 
5. What evaluation if any do you expect from the programme?

6. What is the future of your relationship with the business?

Although the above questions were employed, during the semi-structured interviews researchers used the questions as a basis for initiating and developing conversations with the interviewees that covered subjects the interviewees regarded as important to them. This process was followed in order to allow the emergence of issues considered important by the interviewees that were not directly addressed by the researchers' original questions.

\section{Analysis}

The method employed to analyse the twenty transcribed interviews was 'Constant Comparative Method' (Glaser \& Strauss, 1967; Lincoln \& Guba, 1985). Constant comparative method is an iterative procedure designed for the qualitative analysis of text and is based on 'Grounded Theory' (Glaser \& Strauss, 1967). Grounded theory methodology provides a set of analytic techniques that have been assimilated into most approaches to qualitative research (McLeod, 1995). Writers such as Lofland \& Lofland (1984); Yin (1989); Patton (1990) and Miles \& Huberman (1994) have defined stages in qualitative analysis based on grounded theory that depend on the systematic application of five fundamental ideas: immersion, categorisation, phenomenological reduction, triangulation and interpretation. Analysis of the interview transcripts involved researchers engaging with the five stages of Constant Comparative Method. During 'immersion', the researchers repeatedly read the interview transcripts in order to obtain a high level of familiarity with the data. During this immersion process 90 discernibly different concepts emerged from the data, for example, 'pleasant working environment'; 'route to employment' and 'social mission 
alignment' (Please see Appendix A for a complete list). These concepts were regarded as 'units of analysis'. During 'categorisation', 'units of analysis' with similar meanings were grouped together according to 'rules of inclusion' created in 'propositional statements'. In this procedure, each 'unit of analysis' had to comply with the 'rule of inclusion' for a 'category' to be included in that 'category'. When researchers decided that a 'unit of analysis' did not comply with the 'rule of inclusion' for an existing 'category', a new 'category' was created to accommodate it, leaving room for a continuous refinement in the grouping. This process resulted in 18 'categories' emerging from the 90 'units of analysis'. During 'phenomenological reduction', six 'themes' emerged from the 18 'categories'. As before, each 'category' had to comply with the 'rule of inclusion' for a 'theme' to be included in that 'theme'. When a 'category' did not comply with the 'rule of inclusion' for an existing 'theme', a new 'theme' was created with its own 'rule of inclusion' defined by a new 'propositional statement'. These six emergent 'themes' were subsequently interpreted by the researchers as 'social mission focus', 'heroic social entrepreneur', 'social impact', 'recidivism', 'the programme' and 'programme attendees'. A diagrammatic illustration of this qualitative analysis process is provided for further clarification (see Fig.1). 
Figure 1 - Phases of CCM Analysis for the Interview Data:

Immersion

Units of Analysis

(90)

\section{Categorisation}

Categories (18)

\section{Phenomenological Reduction}

Themes (6)

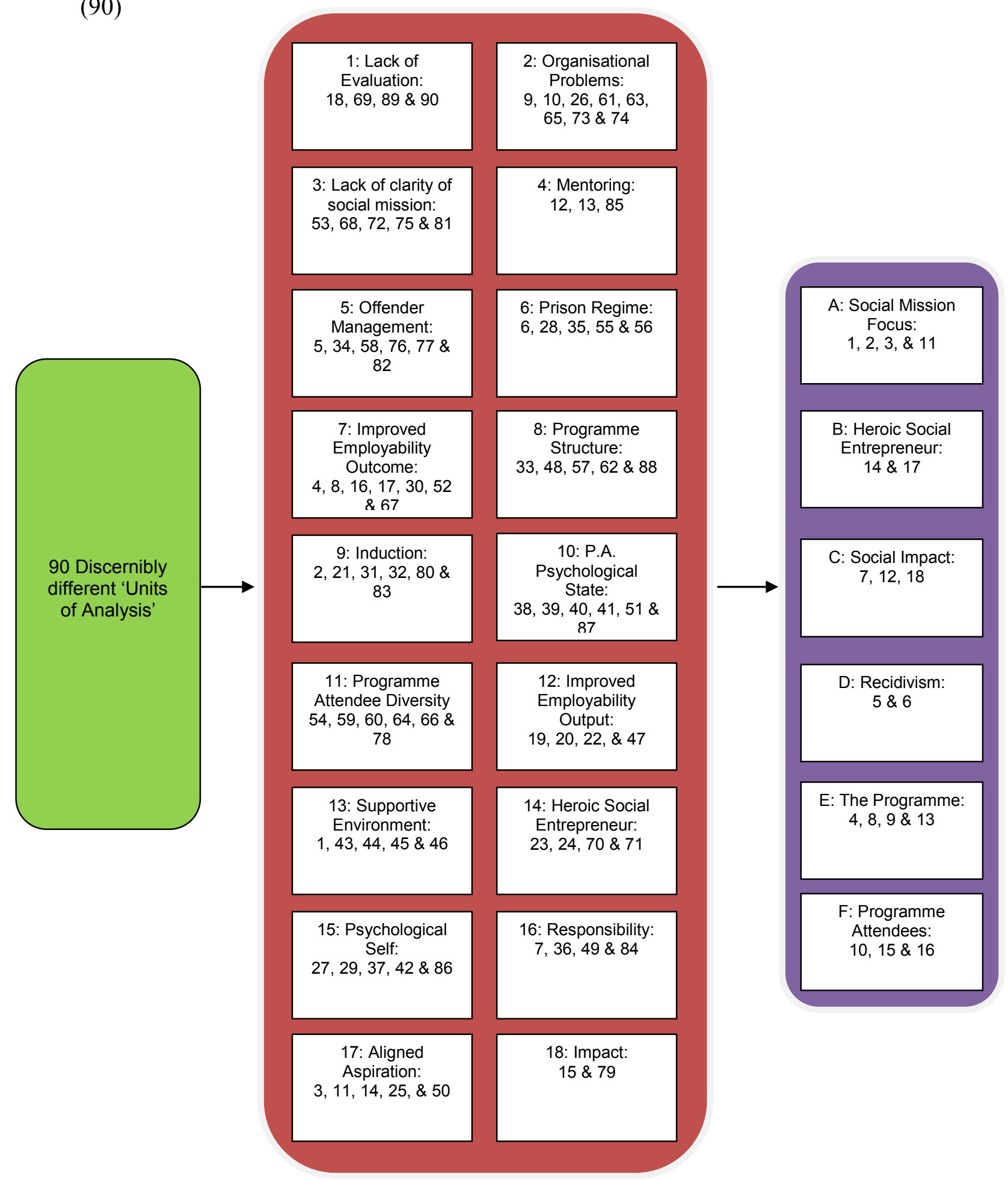

NB. The numbers displayed above in Figure 1 in the 'categories' boxes correspond to the relevant units of analysis contained in that category. The numbers in the 'themes' boxes correspond to the relevant category contained in that theme. 


\section{Results}

The theme 'social mission focus' identified the problems faced by the SEI resulting from having too broad a social mission. The social mission was primarily to support individuals with multidimensional social exclusion problems to reintegrate into society but also included providing financial support for projects in the local community.

'I think some of them [PAs] that have been here have got [mental health] problems that I don't think working here would ever help. They've got problems deep down, and I don't think that would help, no matter what they done working here.' (Staff 7)

The theme 'heroic social entrepreneur' drew attention to the pivotal role played by the social entrepreneur and how he was perceived as a messianic figure.

I think [the social entrepreneur] deserves a lot of credit for what he and the other guys have done. They've come in, they've set this up, and they're hell bent on making it work. Certainly [the social entrepreneur] is like the Messiah,' (Staff 2)

The theme 'social impact' revealed that in spite of there being no formal evaluation of any social impact resulting from the SEI, there were psychological benefits (outcomes) for the PAs.

'And the last four weeks, they [a group of PAs] were part of a group of people, and everybody treats them as a part of a group. You can see them, like the shoulders go up and the heads go up. All of a sudden, amongst all these grown men they're standing 
beside them, doing the same as them and being appreciated for it. Which is nice, it's nice to see.' (Staff 10)

The theme 'recidivism' revealed the multidimensional social exclusion problems prisoners suffered from and how those problems can impact upon prisoners' reintegration to society.

'There are three or four key factors with the prisoner. Can't read, can't write, can't get a job, can't get a bank account, and can't get a house. So, if you can tap into any of those areas, you're breaking that cycle and making it immediately easier for that guy to settle down. He comes out of prison and he's got no idea how he's going to break that cycle, he doesn't know. So he goes straight back to the street, or he goes straight back to his mates, straight back to the peer pressure, and he's back on the cycle of re offending again. We've got to break those key factors.' (Referral Agency Representative)

The theme 'the programme' revealed how working alongside existing staff enabled the PAs to learn by osmosis.

'It's just being by the side of somebody as it's being done, and they're showing me, and I just took it from there. Since I've been here I've learned how to order pick, think ahead on, re palletising, think ahead of how to actually put a consignment together on the pallet so that it's easiest to be picked later on when you're picking. If you're willing to learn, there are more than enough people here willing to teach you.' (PA2) 
The theme 'programme attendees' revealed that although the programme did help PAs feel included within their groups in the programme there was some doubt as to whether this would ultimately transform into inclusion in wider society.

I've gotten used to being around here [the social enterprise], I know how they operate, and I've gotten to know the staff and everything, and they know me. I think if I moved to somewhere else, I'd have to make new relationships with other people, which for me with Aspergers, that's quite difficult.' (PA5)

\section{Discussion}

In the current study, the emergent themes reveal that the social entrepreneur's 'vision' to reintegrate socially excluded individuals with multidimensional exclusion problems into society whilst at the same time providing financial support to his local community, did cause some problems for his 'untrained' staff. The multidimensional nature of the social exclusion that some of the PAs experienced left the staff feeling unqualified to provide the help the PAs required. However, in spite of these problems, the themes also reveal psychological benefits (e.g., self-esteem) experienced by the PAs. The referral agency's representative provided insight into the prisoner PAs' multidimensional social exclusion problem. However, the effectiveness of learning by osmosis alongside the warehouse staff in a 'real' working environment is demonstrated. Most of the PAs in the current study could be described as belonging to 'lower levels of the dimension of exclusion' (Teasdale, 2010: 100), which explains why they expressed feelings of inclusion within the context of the SEI but expressed trepidation when contemplating wider society. It is difficult to imagine that self-employment would be a viable option for individuals with this level and complexity of social exclusion. 
These findings support prior research that called for a clearer understanding of the complex multidimensional concept of social exclusion before over optimistically claiming that small business can significantly combat social exclusion (Blackburn and Ram, 2006; Teasdale, 2010; Amin, 2009). The themes revealed in the current study also highlight the effectiveness of an inductive approach in providing a more complete picture of the efficacy of an SEI than testing prior theories and/or collecting quantitative data. This finding lends support to prior research with similar findings (Teasdale, 2010; Lane and Castile, 2011).

The results of the current study demonstrate the 'holistic' perspective of SEI benefits that can be revealed by eliciting the views of a wider group of stakeholders. In the current study, the SEI was delivered by warehouse staff with no prior training in programme delivery but this enabled a 'real' working environment, to which the PAs responded well. This 'real' working environment seemed to address the problem of loss of work ethic related to long term unemployment, exacerbated by limited past work experience. The lack of work ethic generated by long-term unemployment is identified by the warehouse staff and PAs and both acknowledge the reversal of the PAs' attitude to work and job seeking.

'So you've got young lads, nineteen, twenty, who have never done a day's work since they left school. But you can see them changing and benefiting from it [the SEI]. They start getting a bit of a work ethic, and it's nice to see that [work ethic] by the end of the time they leave.' (Staff 4)

'I weren't that keen on getting one [a job]. I woke up, guaranteed I'd probably have a dodgy cigarette and then just not be bothered for the rest of the day, going out and looking for a job. And then, now, it's just like: "I want a job!'”. '(PA3) 
The change in job-seeking motivation described by the staff and the PA above resonates with that of 'goal orientation' reported in Fergus and Islam (2008) but the outcome in the current study was achieved by PAs working alongside untrained warehousemen in a 'real' working environment. This 'real' working environment has cost benefits over providing space, equipment, clinical and case management staff, and employing professionals (e.g. graphic design instructor, staff from an art's institute and two clinical mentors) as described in Fergus and Islam (2008). Furthermore, increasing job-seeking motivation in these hard to reach longterm unemployed may be a more realistic goal than self-employment (Blackburn and Ram, 2006).

Unfortunately, the SEI in the current study failed to formally evaluate their social impact because they did not keep written records of output (i.e. jobs secured by PAs) but in spite of this failure to record employment output the SEI could be considered to be Type A: 'intermediate companies', which act as a "bridge" to the normal labour market (Vidal, 2005). The SEI accomplished this by improving the employability of the PAs in the warehousing industry through training them in general warehouse skills. Further output was possible because PAs also had the opportunity to gain forklift truck driving licenses and Health and Safety certificates.

'I think everyone who's come so far has had a fork lift license out of us. I think it's quite important to have a reasonably useful skill when you leave as well, Now they leave with a fork lift license, then they're much more employable.' (Staff 3) 
The lack of formal evaluation of the SEI meant there was no documented evidence of output but according to the staff and the social entrepreneur some PAs did find employment in the warehousing sector. Even for PAs who ultimately were unable to find employment in the short term, there were significant outcome benefits in relation to self-esteem.

'They say that I'm a hard worker. The best one [feedback comment] I've had was "You're something special", so yes...... When they say comments like that, it makes me feel really good about myself. We have a laugh, we're all just in the warehouse, I do my job, and the time flies when you're doing it. It's all good in my eyes because it changed me for the good. I do [feel part of a team] because they actually respect me 'cos I'm a hard worker.' (PA3)

This increase in self-esteem provided by the SEI and revealed in the current study, helps to combat social exclusion and lends support to Teasdale (2010) and Hazenberg et al. (2013), which indicated the importance of revealing qualitative outcomes in developing the understanding of the overall effects of SEIs on social exclusion.

I think the main thing I have is a confidence issue when I talk to people. A while ago it was really hard for me to just talk to a random person out of the blue. But at the moment, I'm ok for this. I didn't used to be able to get jokes at all, before I started, but now I think I understand a bit better, when people take the mick out of other people and when they take the mick out of me, I kind of originally didn't like that, I took offence to everything anyone would say to me. But now I understand when they're messing around or being serious.' (PA5) 
The current research also addresses the call by Vidal (2005) for more investigation into the role of the social entrepreneur in developing social enterprises and SEIs. The social entrepreneur who founded and runs the SE, which hosts the SEI programme forming part of the current study, falls into the category of 'heroic social entrepreneur' and his 'vision' drives the SE and shapes the SEI. Although he doesn't accept the need to record output, outcome, and impact (McLoughlin, et al, 2009), the findings of the current research indicate substantial benefits for the PAs involved in the SEI programme. The SEI does fulfil a need for these hard to reach socially excluded individuals and as such is effective and echoes prior research that calls to support the efforts of these 'heroic social entrepreneurs' (Leadbeater, 1997; Spinoza et al, 1997; Dees et al, 2001; Dart, 2004; Nicholls, 2006). This type of SE and the SEI it provides is perhaps something of a hybrid and will only provide support for a limited number of individuals but nevertheless is effective in this specific situation.

'You know I want it [the Social Enterprise] to be a proper organisation that will develop and grow, and provide this type of benefit in different places. Is it ever going to be churning out thousands of people a week being retrained? No, because that is not what I believe. I don't just want to be another organisation out there chasing funding and producing certificates.' (Social Entrepreneur)

\section{Summary}

The current research identified a hybrid type of SEI that evolved from the 'vision' of a 'heroic social entrepreneur' (Dees et al, 2001; Dart, 2004). The social entrepreneur has established a social enterprise, which generates financial surplus in order to fund an effective SEI. Although formal evaluation of the social mission does not take place at the SE, the 
current research provides evidence of both output and outcome benefits for PAs resulting from their engagement in the SEI. The SEI is undertaken with individuals who may be regarded as being from the 'lower levels of the dimension of exclusion' (Teasdale, 2010: 100) and as such are from hard to reach socially excluded groups. This hybrid type of SEI, which seeks to reintegrate socially excluded individuals back into the formal labour market through the 'real-life' development of work ethic alongside formal training, could be what is required to support hard to reach socially excluded groups. Additionally, such an approach could make an impact on the issues that prevent small business from significantly combating social exclusion (Blackburn and Ram, 2006).

\section{References}

Amin, A. (2009) Extraordinarily ordinary: working in the social economy, Social Enterprise Journal, 5(1), 30-39

Blackburn, R. and Ram, M. (2006). Fix or Fixation? The contributions and limitations of entrepreneurship and small firms to combating social exclusion, Entrepreneurship and Regional Development: An International Journal, 18(1), 73-89.

Borzaga, C. \& Defourny, J. (eds.), (2001), The Emergence of Social Enterprise, Routledge, London.

Burnett, R (2004), To re-offend or not to re-offend? The Ambivalence of convicted property offenders. In Maruna, S. and Immarigeon, R. (eds) After Crime and Punishment: Pathways to Offender Reintegration, Cullompton: Willan 
Cabinet Office of the Third Sector. (2006). Social enterprise action plan: Scaling new heights. London, England: Office of the Third Sector.

Campi, S., Defourny, J. \& Grégoire, O., (2006), Work-Integration Social Enterprises: Are they Multiple Goal \& Multi-Stakeholder Organisations? In Nyssens, M. ed., 2006, Social Enterprise, pp. 29-49, Routledge Publishing, Oxon, UK.

Cohen, S. (1985), Visions of Social Control, Cambridge: Policy Press.

Dart, R. (2004) The legitimacy of social enterprise, Nonprofit management and Leadership, $14(4), 411-24$

Dees, J.G., Emerson J. and Economy, P. (2001) Enterprising Nonprofits: A Toolkit for Social Entrepreneurs, Willey, New York, NY.

Defourny, J. \& Nyssens, M., (2006), 'Defining Social Enterprise'. In Nyssens, M. ed., 2006, Social Enterprise, pp. 3-26, Routledge Publishing, Oxon, UK.

Ferguson, K.M and Islam, N. (2008) Conceptualising Outcomes with Street-Living Adults: Grounded Theory Approach to Evaluating the Social Enterprise Intervention, Qualitative Social Work, 7(2), 217-237.

Gardin, L., (2006), A Variety of Resource Mixes Inside Social Enterprise. In Nyssens, M. ed., 2006, Social Enterprise, pp. 111-136, Routledge Publishing, Oxon, UK. 
Glaser, B. G. and Strauss, A. L. (1967), The Discovery of Grounded Theory, Chicago. IL: Aldine.

Hannah-Moffat, K. (2005), Criminogenic Needs and the Transformative Risk Subject: Hybridizations of Risk/Need in Penalty, Punishment and Society, 7(1), 29-51.

Hazenberg, R., (2012), Work integration social enterprise: a NEET idea, Doctoral Thesis, The University of Northampton.

Hazenberg, R., Seddon, F. \& Denny, S., (2013), Investigating the outcome performance of work-integration social enterprises (WISEs): Do WISEs offer 'added value' to NEETs? Public Management Review, Taylor \& Francis (DOI: $\underline{10.1080 / 14719037.2012 .759670)}$.

Lane, M.D. and Casile, M (2011) Angels on the head of a pin: The SAC framework for performance measurement in social entrepreneurship ventures, Social Enterprise Journal, $7(3), 238-258$

Leadbeater, (1997) The Rise of the Social Entrepreneur, Demos, London.

Lincoln, Y. \& Guba, E. (1985), Naturalistic Inquiry, Beverly Hills, CA: Sage.

Lofland, J., \& Lofland, L. (1984) Analyzing Social Settings: A Guide to Qualitative Observation and Analysis, $2^{\text {nd }}$ Edition. Belmont, CA: Wadsworth. 
Mawby, R., Crawley, P. and Wright, A. (2007), Beyond 'Polibation' and Towards 'Prisipolibation' Joint Agency Offender Management in the Context of the Street Crime Initiative, International Journal of Police Science and Management, 9(2), 122-134.

McLeod, J. (1994), Doing Counselling Research, London: Sage.

McLoughlin, J., Kaminski, J., Sodagar, B., Khan, S., Harris, R., Arnaudo, G. and Mc Brearty, S. (2009) A strategic approach to social impact measurement of social capital enterprises: the SIMPLE methodology, Social Enterprise Journal, 5(2), 154-78

McNeill, F. and Weaver, B (2010), Changing Lives? Desistance Research and Offender Management. The Scottish Centre for Crime and Justice Research

Miles, M., \& Huberman, A. (1994), Qualitative Data Analysis: A Sourcebook of New Methods, $2^{\text {nd }}$ edition, London: Sage.

Nichols, A. (2006) Social Entrepreneurship: New Paradigms of Sustainable Social Change, Oxford University Press, Oxford.

Nyssens, M. \& Platteau, A., (2006), Profiles of Workers \& Net Effects of Belgian WISEs. In Nyssens, M. ed., 2006, Social Enterprise, pp. 222-234, Routledge Publishing, Oxon, UK.

Office of the Deputy Prime Minister. (2004). Tackling social exclusion: Taking stock and looking to the future. London, England: Author.Patton, M. Q. (1990). Qualitative Evaluation and Research Methods (2nd Ed.), Newbury Park, CA: Sage Publications, Inc. 
Mawby, R., Crawley, P. and Wright, A. (2007), Beyond 'Polibation' and Towards 'Prisipolibation' Joint Agency Offender Management in the Context of the Street Crime Initiative, International Journal of Police Science and Management, 9(2), 122-134.

Peattie, K., \& Morley, A. (2008). Social enterprises: Diversity and dynamics, contexts and contributions. London, England: Social Enterprise Coalition.

Seddon, F., Hazenberg, R. and Denny, S. (under review) What are the barriers to investing in social enterprises? An investigation into the attitudes and experiences of social entrepreneurs in England, Voluntary Sector Review.

Spear, R. and Bidet, E. (2005) Social enterprises for work integration in 12 European countries: A descriptive analysis, Annals of Public and Cooperative Economics, 76(2), 195231.

Spinoza, C., Flores, R. and Dreyfus, H.L. (1997) Disclosing New Worlds: Entrepreneurship, Democratic Action, and the Cultivation of Solidarity, The MIT press, Cambridge, MA

Teasdale, S. (2010). How can Social Enterprise Address Social Disadvantage? Evidence from an Inner City Community, Journal of Nonprofit \& Public Sector Marketing, 22(2), 89-107.

Vidal, I. (2005) Social Enterprise and Social Inclusion: Social Enterprises in the Sphere of Work Integration, International Journal of Public Administration, 28(9-10), 807-825.

Yin, R.K., (1989), Case Study Research: Design and Methods, London: Sage. 
1. Pleasant working environment

2. Route to Employment

3. Social Mission Alignment

4. Employment Acclimatisation

5. Clean slate

6. Equality

7. Reform

8. Improved Employability

9. Office/Warehouse Disconnect

10. Double-bottom Line

11. Aligned Progression

12. Nurturing

13. Staff Mentoring

14. Belief in Business Plan

15. Re-socialisation

16. Confidence building

17. Work ethic

18. Monitoring

19. Warehousing Skills

20. Qualifications

21. Induction Policy

22. Output Success Criteria

23. Future Plans 
24. Heroic Figure

25. Staff Motivation

26. Prior Experience

27. Motivation

28. Criminal Legacy

29. Job-seeking Self-efficacy

30. Benefits of Work Experience

31. Training Agency Support

32. Unemployment System

33. Sanctions

34. Criminality

35. Prison Support

36. Family Responsibility

37. Qualification Afterglow

38. Biographical Background

39. External Locus of Control

40. Psychological Effects of Unemployment

41. Rejection

42. Self-esteem

43. Inclusivity

44. Teamwork

45. Supportive Environment

46. Emotional Response

47. Self-evaluated Output

48. Learning by Osmosis 
49. Sense of Responsibility

50. Aspiration

51. Dependency

52. Positive Experience

53. Lack of Acknowledgement

54. De-motivated Attendees

55. Dual Environment

56. Prison Regime

57. Training

58. Reoffending

59. Lack of Suitability

60. Suitability

61. Poor Communication

62. Programme Structure

63. Multiple Roles

64. Diversity of PAs Problems

65. Attendance Problems

66. Diversity of PAs

67. Outcome Success Criteria

68. Business/Social Mission Development Conundrum

69. Lack of Evaluation

70. Social Networks

71. Visionary Practicality

72. Unstructured Social Mission

73. Resource Management 
74. University Relationship

75. PA Informed of Social Mission

76. Breaking the Cycle

77. Recidivist Readiness

78. Risk-assessment

79. Impact Success Criteria

80. Lack of Employer Engagement

81. Conflicted Mission

82. 'Siloed' Offender Management

83. The Economy

84. Personal Responsibility

85. Effects of Positive Feedback

86. Well-being

87. Vicious Circle

88. Low Cost of Learning by Osmosis

89. Lack of Accreditation

90. Financial Independence 